\title{
PENGARUH PENAMBAHAN ALKANOLAMIDA TERHADAP SIFAT-SIFAT UJI TARIK VULKANISAT KARET ALAM BERPENGISI KAOLIN
}

\author{
Yudha Widyanata, Indah M.S. Sitorus, Indra Surya \\ Departemen Teknik Kimia, Fakultas Teknik, Universitas Sumatera Utara, \\ Jl almamater Kampus USU Medan 20155, Indonesia \\ Email : yudha.widyanata@ymail.com
}

\begin{abstract}
Abstrak
Dengan menggunakan sistem vulkanisasi semi effisien, Alkanolamida (ALK) dicampurkan ke dalam kompon karet alam berpengisi kaolin pada 1,0; 3,0; 5,0 dan 7,0 bagian per seratus karet (bsk). Penelitian dilakukan untuk menguji pengaruh ALK pada sifat-sifat uji tarik dari kompon karet alam berpengisi kaolin. Dari pengujian tersebut ditemukan bahwa ALK memberikan modulus tarik, kekuatan tarik, dan pemanjangan saat putus yang lebih besar sampai 5,0 bsk dari kadar ALK dan menurun dengan penambahan lebih jauh kadar ALK. Pengukuran kerapatan sambung silang membuktikan bahwa kadar ALK sebesar 5,0 bsk pada sistem karet alam berpengisi kaolin memperlihatkan sifat-sifat tarik yang paling besar dikarenakan pembentukan kerapatan sambung silang yang paling tinggi.
\end{abstract}

Kata kunci : Alkanolamida, karet alam, sifat - sifat uji tarik, kerapatan sambung silang

\begin{abstract}
By using a semi-efficient vulcanization system, Alkanolamide (ALK) was incorporated into kaolin-filled natural rubber compound at 1.0; 3.0; 5.0 and 7.0 parts per hundred rubber (phr). An investigation was carried out to examine the effect of ALK on tensile properties of the kaolin filled-natural rubber compound. It was found that ALK exhibited higher tensile modulus, tensile strength, and elongation at break up to $5.0 \mathrm{phr}$ of ALK loading and then decreased with further increasing of ALK loading. Crosslink density measurement proved that $5.0 \mathrm{phr}$ loading of ALK in the kaolin-filled natural rubber system exhibited greatest tensile properties due to its highest crosslink density formation.
\end{abstract}

Keywords : alkanolamide, natural rubber, tensile properties, crosslink density

\section{Pendahuluan}

Pada industri karet, pengisi-pengisi dapat dibagi menjadi pengisi hitam dan putih. Pengisi hitam adalah karbon, dan pengisipengisi putih adalah kalsium karbonat, kaolin, silika presipitat, talkum, barit, wollastonite, mika. Dari kesemua pengisi putih, 3 pengisi yang yang paling sering digunakan, secara jumlah dan kegunaan, adalah kalsium karbonat, presipitat silika, dan kaolin. Untuk banyak penggunaan, kaolin dan pengisi-pengisi putih yang lain bukan merupakan pilihan yang baik, karena tingkat penguatannya yang tidak memadai. Masalah utamanya adalah kimia permukaannya yang lebih polar dan terhidrasi ketimbang karbon, dan menyebabkan kaolin dan pengisi-pengisi putih yang lain sulit untuk menyebar dan berinteraksi dengan hidrokarbon dari karet. Sejumlah teknologi telah dilakukan untuk meningkatkan reaktivitas dari pengisipengisi putih dengan fasa karet. Salah satunya adalah memanfaatkan zat penggabung silana. Zat penggabung mengubah permukaan pengisipengisi yang polar. Pengisi-pengisi polar yang dimodifikasi memberikan permukaanpermukaan aktif secara kimia yang dapat mengambil bagian pada vulkanisasi, memberikan pasangan ikatan-ikatan antara silana, fasa karet dan pengisi-pengisi $[5,7,8]$.

Berdasarkan hal tersebut diatas peneliti tertarik untuk meningkatkan reaktivitas dari pengisi penguat kaolin terhadap karet alam, yaitu dengan penggunaan Alkanolamida yang akan bertindak sebagai bahan aditif yang membantu untuk meningkatkan interaksi kaolin dengan karet alam. Bahan tersebut adalah senyawa amida tersier, yang diperoleh melalui proses sintesa amidasi, yaitu dengan mereaksikan asam-asam lemak yang berasal dari minyak kelapa sawit dengan dietanolamina $\mathrm{NH}\left(\mathrm{CH}_{2} \mathrm{CH}_{2} \mathrm{OH}\right)_{2}$ dengan menggunakan katalis $\mathrm{CH}_{3} \mathrm{ONa}$. Molekul-molekul amida asam lemak tersebut memiliki sifat gabungan yang unik, karena rantai hidrokarbonnya yang panjang bersifat non-polar sedangkan gugus amidanya bersifat sangat polar. Dengan metode ini diharapkan kaolin dapat dipakai sebagai pengisi penguat alternatif dengan efisiensi penguatan yang lebih baik lagi. Untuk meningkatkan efek penguatan dari kaolin terhadap karet alam dengan cara mengurangi 
kepolarannya, yaitu dengan menambahkan Alkanolamida kedalam kompon karet alam berpengisi kaolin. Disebabkan oleh sifat kimia permukaan dari pengisi kaolin yang polar, maka ini merupakan kelemahan bagi kaolin jika digunakan sebagai pengisi penguat alternatif bagi karet alam. Maka kepolaran pengisi tersebut harus dikurangi yaitu dengan menambahkan bahan Alkanolamida kedalam kompon karet alam berpengisi kaolin.

\section{Teori}

Pengisi-pengisi biasanya digunakan untuk meningkatkan sifat-sifat mekanikal dari vulkanisat karet alam seperti kekuatan tarik (tensile strength), ketahanan terhadap pengikisan dan pengoyakan (resistances to abrasion and tearing) atau untuk memurahkan ongkos suatu produk karet (cheapen the cost of product). Pengisi-pengisi juga mempengaruhi sifat-sifat viskoelastis (viscoelastic properties) dan kekuatan kompon karet. Berdasarkan efek penguatan terhadap sifat-sifat karet (rubber properties), maka pengisi dapat dikelompokkan menjadi 3 yaitu penguat (reinforcing), semi penguat dan bukan penguat (non reinforcing). Pengisi penguat (reinforcing filler) digunakan untuk meningkatkan sifat-sifat mekanikal vulkanisat karet alam seperti yang telah dijelaskan diatas. Pengisi bukan penguat dipakai untuk memurahkan ongkos produksi, dan memudahkan pemrosesan. Pengisi bukan penguat juga dapat menyebabkan peningkatan kekerasan, penurunan kekuatan-kekuatan tarik dan koyak, resistansi pengikisan, dan resiliensi dari vulkanisat karet. Kalsium karbonat $\left(\mathrm{CaCO}_{3}\right)$, barium sulfat, dan kaolin (clay) adalah contoh-contoh pengisi bukan penguat bagi karet $[1,2,4]$.

\section{Metodologi Penelitian}

Penelitian dilaksanakan di Laboratorium

Kimia Organik Departemen Kimia F-MIPA USU dan Laboratorium PT Industri Karet Deli, Medan.

Tabel 1 menunjukkan bahan yang dipakai untuk sistem vulkanisasi sulfur terakselerasi semi efisien. Bahan yang digunakan untuk membuat Alkanolamida yaitu dietanolamin, RBDPS (Rifinery Bleaching Deodorant Product Stearin), natrium metoksida, metanol, dietil eter, natrium sulfat anhydrous, natrium klorida jenuh. Sementara itu untuk melakukan uji tarik bahan yang digunakan yaitu Alkanolamida, karet alam, $\mathrm{ZnO}$ asam stearat, MBTS (Benzothiazolildisulfide), IPPD (N-Isopropil$N^{\prime}$-phenil-phenilena-amnia), sulfur, dan kaolin.
RBDPS ditimbang sebanyak 91,6 gram kemudian dimasukkan kedalam 1 L labu leher tiga lalu ditambahkan dietanolamin sebanyak 42,16 gram, dirangkai alat refluks, dihidupkan hotplate, dibiarkan RBDPS dan dietanolamin bercampur, setelah bercampur ditambahkan campuran metanol dan natrium metoksida (40 $\mathrm{ml}: 10$ gram) lalu dipanaskan pada suhu 70-80 ${ }^{\circ} \mathrm{C}$ selama 5 jam. Setelah selesai dibiarkan beberapa menit sampai suhu kamar, selanjutnya diekstrasi dengan dietil eter sebanyak 200 gram, dicuci dengan $\mathrm{NaCl} 50 \mathrm{ml}$ sebanyak 3 kali. Hasilnya akan didapati 2 lapisan. Lapisan atas adalah Alkanolamida dan lapisan bawah natrium metoksida. Lapisan bawah dibuang dan lapisan atas diambil lalu ditambahkan natrium sulfat anhydrous dibiarkan selama 1 hari. Kemudian disaring dengan kertas saring, filtratnya diuapkan dengan alat vaporator sehingga didapat Alkanolamida dalam bentuk semi padat (gel).

Pengujian bengkak (swelling test) pada vulkanisat-vulkanisat dilakukan dengan melarutkannya didalam toluen berdasarkan ISO 1817. Potongan-potongan yang akan di uji (30 $\mathrm{mm} \times 5 \mathrm{~mm} \times 2 \mathrm{~mm}$ ) di timbang menggunakan timbangan elektrik dan di masukkan kedalam toluen hingga kesetimbangan, yang mana memakan waktu selama 72 jam pada temperatur ruangan. Sampel-sampel dikeluarkan dari cairan, toluen yang masih ada di permukaan sampel dihilangkan, lalu ditimbang. Sampel-sampel tersebut lalu dikeringkan di dalam oven pada temperatur 60 ${ }^{\mathrm{O}} \mathrm{C}$ sampai berat konstan didapat. Hasil pembengkakan digunakan untuk menghitung berat molekul antara 2 buah sambung silang (Mc) dengan menggunakan persamaaan FloryRehner [9]:

$$
\mathrm{Mc}=\frac{-\rho_{\mathrm{p}} \mathrm{V}_{\mathrm{s}} \mathrm{V}_{\mathrm{r}}^{1 / 3}}{\ln (1-\mathrm{Vr})+\mathrm{Vr}+\chi \mathrm{V}_{\mathrm{r}}^{2}}
$$

$\mathrm{Vr}=\frac{1}{1+\mathrm{Qm}}$

Dimana $\rho$ adalah kerapatan karet ( $\rho$ dari karet alam $\left.=0,92 \mathrm{~g} / \mathrm{cm}^{3}\right), V_{\mathrm{s}}$ adalah volum molar toluen $\left(\mathrm{V}_{\mathrm{s}}=106,4 \mathrm{~cm}^{3} / \mathrm{mol}\right), \mathrm{V}_{\mathrm{r}}$ merupakan fraksi volum dari polimer pada sampel yang membengkak. $\mathrm{Q}_{\mathrm{m}}$ merupakan peningkatan berat dari campuran di dalam toluene dan $\chi$ merupakan parameter interaksi antara jaringan karet dengan pelarut $(\chi$ dari karet alam $=0,039$ ). 
Tabel 1. Sistem vulkanisasi sulfur terakselerasi semi-effisien

\begin{tabular}{|c|c|c|c|c|c|c|}
\hline No & Nama Bahan & $\begin{array}{c}\text { Kompon } \\
\text { A (bsk)* }\end{array}$ & $\begin{array}{c}\text { Kompon } \\
\text { B (bsk)* }\end{array}$ & $\begin{array}{c}\text { Kompon } \\
\text { C (bsk)* }\end{array}$ & $\begin{array}{c}\text { Kompon } \\
\text { D (bsk)* }\end{array}$ & $\begin{array}{c}\text { Kompon } \\
\text { E (bsk)* }\end{array}$ \\
\hline 1 & Karet alam & 100,0 & 100,0 & 100,0 & 100,0 & 100,0 \\
\hline 2 & ZnO & 5,0 & 5,0 & 5,0 & 5,0 & 5,0 \\
\hline 3 & Asam stearat & 3,0 & 3,0 & 3,0 & 3,0 & 3,0 \\
\hline 4 & MBTS & 2,0 & 2,0 & 2,0 & 2,0 & 2,0 \\
\hline 5 & IPPD & 2,0 & 2,0 & 2,0 & 2,0 & 2,0 \\
\hline 6 & Sulfur & 2,0 & 2,0 & 2,0 & 2,0 & 2,0 \\
\hline 7 & Kaolin & 30 & 30 & 30 & 30 & 30 \\
\hline 8 & Alkanolamida & 0 & 1 & 3 & 5 & 7 \\
\hline
\end{tabular}

* bagian per seratus karet alam (bsk)

Pencampuran karet alam dan bahan-bahan lain dilakukan pada two-roll mill. Karet alam, Alkanolamida, kaolin dan bahan-bahan lainnya dicampur sampai mencapai keadaan homogen pada suhu yang dijaga konstan pada $\pm 65-75$ ${ }^{0} \mathrm{C}$ selama \pm 25 menit untuk satu siklus pencampuran. Sampel senyawa karet yang berupa lembaran disimpan dengan kondisi \pm 21-25 ${ }^{\circ} \mathrm{C}$ selama \pm 24 jam. Didalam suatu freezer tertutup sebelum dilakukan pengujian terhadap sifat-sifat uji tarik. Penyediaan dan pengujian sampel. Sampel-sampel berbentuk dumbel dipotong dari lembaran vulkanisat karet pada ketebalan $2 \mathrm{~mm}$ dengan pisau pemotong yang juga berbentuk dumbel. Panjang dan lebar sampel $31-35 \mathrm{~mm}$ dan 6,2 - 6,4 mm. Sampel ini diuji sifat uji tariknya. Prosedur sifat-sifat uji tarik dilakukan dengan melakukan standarisasi ASTM D 412-92 Test method A yaitu dengan menggunakan Tensometer Monsanto (Model T10) yang beroperasi dengan kecepatan $50 \mathrm{~cm} / \mathrm{min}$. Sifatsifat uji tarik dilakukan dengan melakukan pembacaan kekuatan tarik (Tensile Strength) dan persentasi pemanjangan pada saat putus (\% elongation at break) yang terekam dalam display dari Tensometer T10 pada akhir setiap pengujian.

\section{Hasil dan Pembahasan}

Adapan hasil FT-IR dari Alkanolamida disajikan pada gambar 1. Hasil dari pembuatan Alkanolamida dibuktikan melalui bilangan gelombang yang terbentuk dari gugus karbonil amida yang didukung oleh munculnya pita serapan pada bilangan gelombang C-N (1364,48 $\left.\mathrm{cm}^{-1}\right)$. Pada bilangan gelombang daerah $3370,14 \mathrm{~cm}^{-1}$ menunjukkan vibrasi gugus $\mathrm{C}=\mathrm{C}$. Pada bilangan gelombang 1615,44 $\mathrm{cm}^{-1}$ yang merupakan vibrasi stretching $\mathrm{C}=\mathrm{O}$. Pada bilangan gelombang 2852,20 $\mathrm{cm}^{-1}$ merupakan gugus - $\left(\mathrm{CH}_{2}\right)$ yang merupakan rantai hidrokarbon alkil rantai panjang [6].

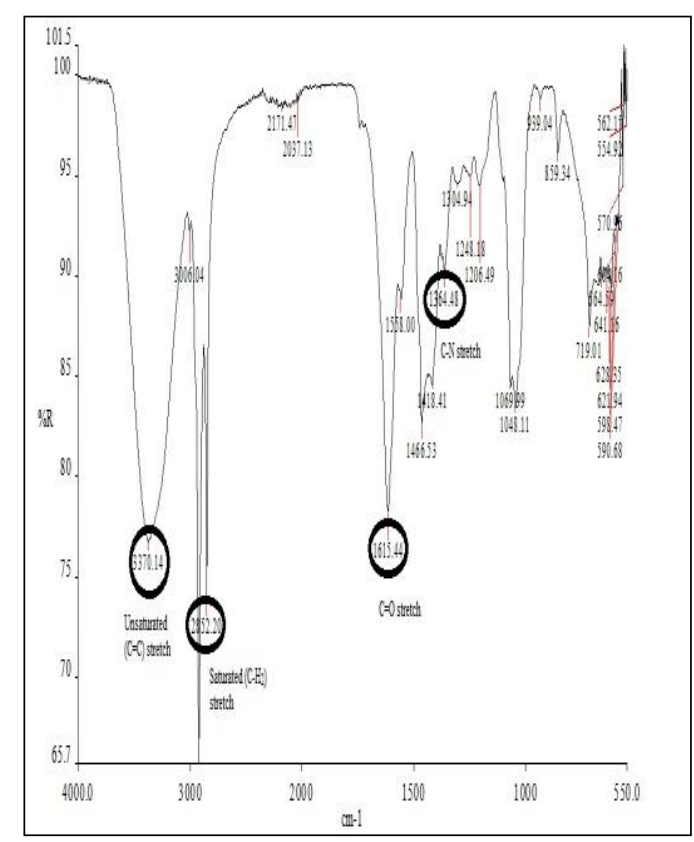

\section{Gambar 1. FT-IR Alkanolamida}

Penambahan Alkanolamida sampai kadar 5 bsk mengalami peningkatan kerapatan sambung silang. Hal ini dapat disebabkan, Alkanolamida dapat bertindak sebagai bahan yang membantu proses atau reaksi sambung silang (curative agent), yaitu dapat membentuk sambung silang tambahan, baik sambung silang secara kimia maupun sambung silang fisikal antara kaolin dengan karet alam. Penambahan sambung silang ini menyebabkan peningkatan kerapatan sambung silang vulkanisat karet [3]. Penambahan yang lebih dari 5 bsk, vulkanisat mengalami penurunan kerapatan sambung silang karena kadar bahan tersebut bertindak sebagai pelarut yang membuat sulfur dan bahan kuratif lainnya melarut ke dalam bahan tersebut, 
sehingga menyebabkan penurunan kerapatan sambung silang bagi vulkanisat karet tersebut.

Gambar 2 menyatakan kerapatan sambung silang.

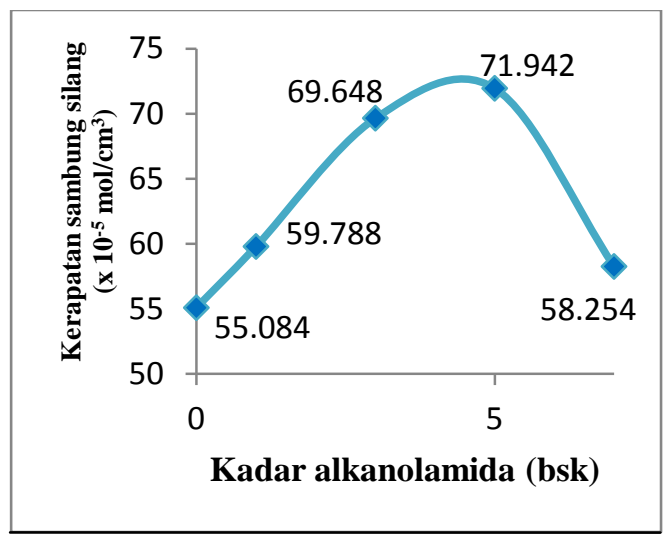

Gambar 2. Kerapatan sambung silang vulkanisat karet alam berpengisi kaolin dan Alkanolamida.

Gambar 3 menunjukkan modulus tensil vulkanisat karet alam berpengisi kaolin dan Alkanolamida.

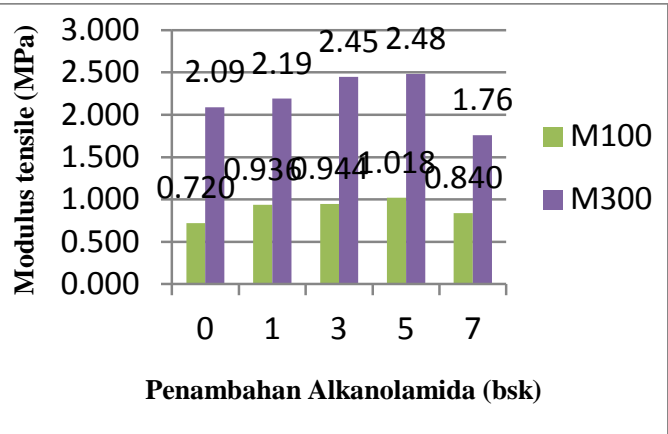

Gambar 3. Modulus tensil vulkanisat karet alam berpengisi kaolin dan Alkanolamida.

Dari kurva modulus tensil, terlihat bahwa penambahan Alkanolamida ke dalam kompon karet alam berpengisi kaolin sampai 5,0 bsk menghasilkan vulkanisat karet alam berpengisi kaolin dan Alkanolamida dengan modulus tensil (M100 dan M300) yang lebih tinggi. Peningkatan nilai modulus tensil ini menyebabkan vulkanisat karet berpengisi tersebut menjadi lebih kaku, efek kekakuan ini disebabkan oleh peningkatan kerapatan sambung silang, melalui peningkatan interaksi baik pengisi kaolin maupun Alkanolamida dengan molekul karet alam, sehingga kerapatan sambung silang meningkat, yang menyebabkan rantai-rantai molekul karet alam susah untuk bergerak. Sehingga dapat dikatakan penambahan Alkanolamida ke dalam kompon karet alam berpengisi kaolin sama saja dengan meningkatkan kerapatan sambung silang dari vulkanisat karet berpengisi tersebut. Penambahan Alkanolamida yang lebih dari 5,0 bsk. menyebabkan nilai M100 dan M300 dari vulkanisat karet berpengisi tersebut menjadi menurun. Hal ini disebabkan jumlah/kadar yang lebih banyak dari Alkanolamida tersebut dapat bertindak sebagai bahan yang dapat melarutkan bahan-bahan kuratif, sehingga menurunkan kerapatan sambung silang yang mungkin dibentuk. Penjelasan ini konsisten dengan efek Alkanolamida terhadap kerapatan sambung silang vulkanisat karet alam berpengisi kaolin dan Alkanolamida.

Untuk melihat seberapa kuat karet alam maka dilakukan uji kekuatan tarik yang disajikan pada gambar 4 .

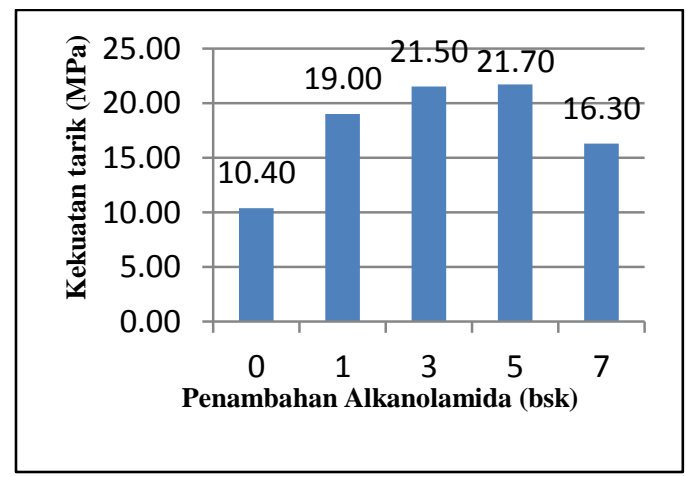

Gambar 4. Kekuatan tarik vulkanisat karet alam berpengisi kaolin dan Alkanolamida.

Kekuatan tarik dari vulkanisat karet alam berpengisi kaolin meningkat dengan penambahan Alkanolamida dari 1,0 bsk hingga 5,0 bsk. Peningkatan kekuatan ini dapat disebabkan karena Alkanolamida dapat bertindak sebagai bahan yang dapat meningkatkan kerapatan sambung silang dari vulkanisat karet alam berpengisi kaolin. Peningkatan penambahan Alkanolamida lebih lanjut menyebabkan penurunan kekuatan tarik vulkanisat karet alam berpengisi kaolin tersebut, Penjelasan ini konsisten dengan efek Alkanolamida terhadap kerapatan sambung silang vulkanisat karet alam berpengisi kaolin dan Alkanolamida.

Gambar 5 menunjukkan pemanjangan saat putus dari vulkanisat. Pengaruh pemanjangan saat putus dari vulkanisat karet alam berpengisi kaolin meningkat dengan penambahan Alkanolamida. Sehingga dapat dikatakan penambahan Alkanolamida ke dalam kompon karet alam berpengisi kaolin dapat meningkatan ekstensibilitas dari vulkanist karet 
berpengisi tersebut. Efek dari bahan tersebut sama seperti bahan pemlastis (minyak) yang plastizicer.

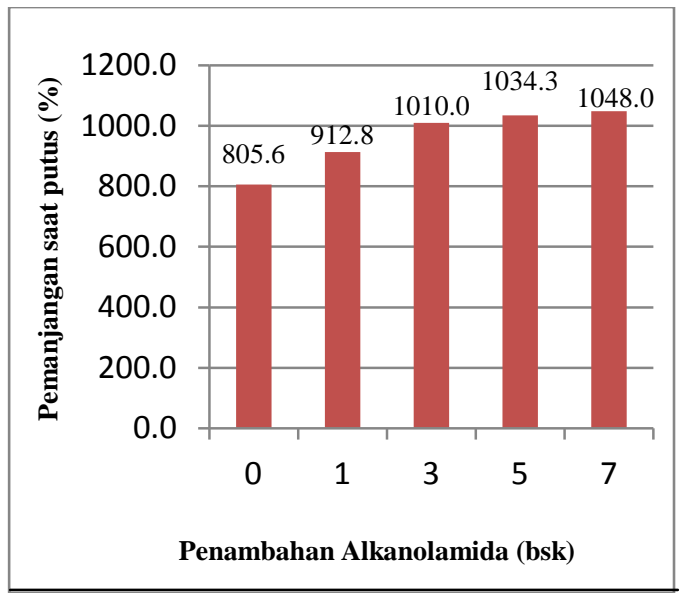

Gambar 5. Pemanjangan saat putus vulkanisat karet alam berpengisi kaolin dan Alkanolamida.

\section{Kesimpulan}

Penambahkan Alkanolamida kedalam kompon karet alam berpengisi kaolin, hingga 5 bsk menyebabkan kenaikan kekuatan tarik, modulus tensil dan sambung silang dari vulkanisat karet alam berpengisi kaolin. Penambahan yang lebih besar dari 5 bsk menyebabkan kekuatan tarik, modulus tensil dan sambung silang dari vulkanisat karet alam berpengisi kaolin menjadi menurun. Kemungkinan hal ini disebabkan Alkanolamida telah bersifat sebagai bahan pelarut yang dapat melarutkan bahan-bahan

\section{Ucapan Terimakasih}

Pada kesempatan ini Peneliti mengucapkan terimakasih kepada Laboratorium Kimia Organik F-MIPA USU dan PT Industri Karet Deli yang telah membantu didalam penyediaan tempat penelitian didalam membuat Alkanolamida dan pengujian terhadap sifat-sifat uji tarik dari vulkanisat.

\section{Daftar Pustaka}

[1] A.D. Thorn \& R.A. Robinson. In Rubber Product Manufacturing Technology. Bhowmick, A.K. et al., ed, New York : Marcel Dekker, Inc., 1994, p.3.

[2] B.B. Boonstra. Carbon black and non black in rubber technology. Morton, M ed., New York : Van Nostrand Reinhold Company, 1973, p. 51-86.
[3] G. Kraus, "Interactions of elastomers and reinforcing fillers," Rubber Chem Technol, XXXVIII November, 1965, p. 1070-1114.

[4] J.B. Horn. Materials for compounding and reinforcement. In rubber technology and manufacture. Blow, C.M.ed. London : Butterworth \& Co. Ltd. 1971, p. 174-226.

[5] M.P. Wagner, "Heat Generation and Rubber-Filler Coupling Bonds," Rubber Chem Technol, XLVII September, 1974, p. 697-716.

[6] M.R. Silverstein. Spectrometric Identification of Organic Compounds. (New York : John Wiley \& Son.1997), p.166-170.

[7] M.W. Ranney \& C.A. Pagano, "Silane Coupling Agent Effects In Ethylene Propylene Diene Terpolymer," Rubber Chem Technol, XLIV, September, 1971, p. 1080-1092.

[8] P.E. Pinter \& Mc. Gill, C.R, "Comparing rubber fillers in an energy conscious economy," Rubber World, CLXXVII Februari, 1978, p. 30-37.

[9] P.J. Flory. And J. Rehner, "Statistica Mechanics of Crosslink Polymer Network II. Swelling," J. Chem. Phys, XI November, 1943, p 521. 